\title{
Analysis of the Effect of Uganda's 2011 Government Spending Shock on Key Macroeconomic Variables
}

\author{
Margaret Magumba
}

\begin{abstract}
Economic theory suggests that when an economy experiences a government spending shock, it reacts in a specific manner. This paper tests this supposition by analyzing the response of Uganda's aggregate output, inflation and real policy interest rates to the country's 2011 government spending shock, in contrast with what the AD/AS economic model suggests. The analysis indicates that following the shock, all the aforementioned economic variables responded in line with the model's stipulations, and the economy experienced a crowding out effect on net exports.
\end{abstract}

Keywords: government spending shock, AD/AS model, policy interest rate, inflation rate, aggregate output, GDP, government expenditure

DOI: $10.7176 / J E S D / 10-6-11$

Publication date:March $31^{\text {st }} 2019$

\section{Introduction}

1.1 Overview

In 2011, Uganda experienced a positive shock in government spending. This paper analyses the response of aggregate output, the inflation rate and real policy interest rate, in contrast with what the AD/AS model suggests. The paper also analyses the response of net exports to the government spending shock.

The findings indicate that Uganda's aggregate output, inflation rate and real policy interest rate all responded in line with the $\mathrm{AD} / \mathrm{AS}$ economic theory following the 2011 government spending shock. They also show that the economy experienced a crowding out effect on net exports.

\subsection{Uganda's Government Spending Pattern}

As illustrated in Figure 1 below, Uganda's annual government spending growth was relatively stable between 2000 and 2009, but it experienced a conspicuous spike in 2011, and consequently, the years following displayed a seemingly turbulent pattern.

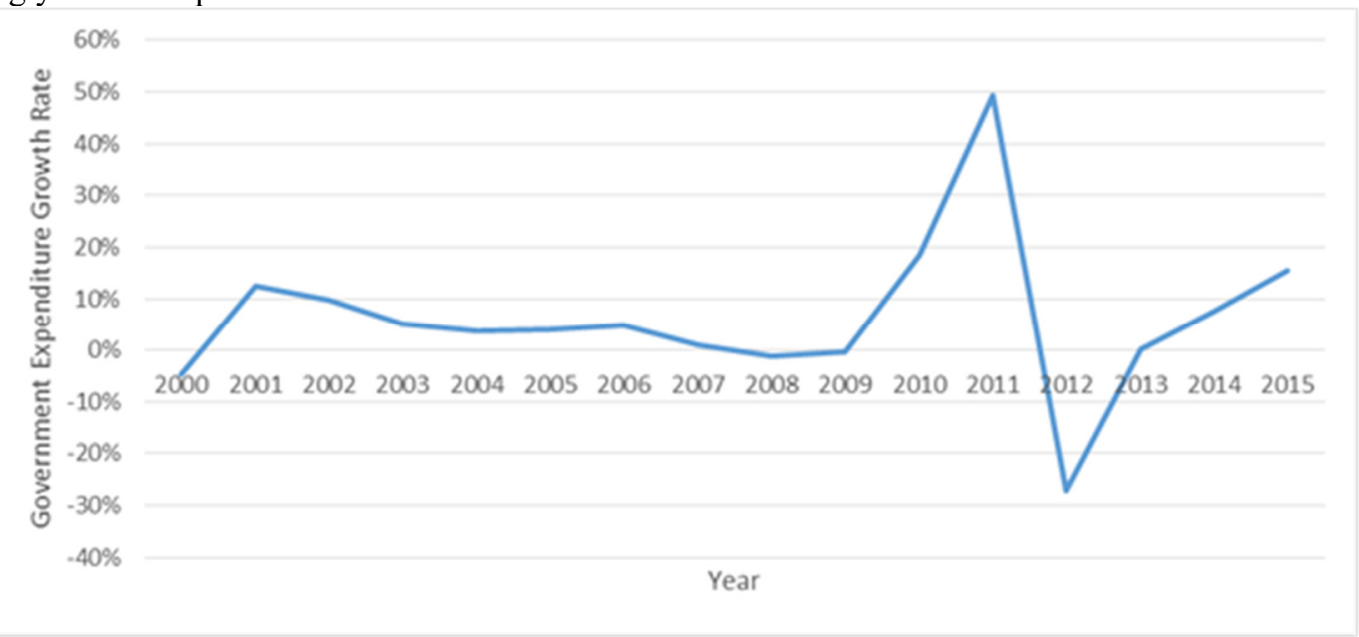

Data Source: World Bank Databases

Figure 1: Uganda's Annual Government Spending Growth Rate (2000 - 2015)

According to Uganda's Ministry of Finance (2011, pp 19), “the terrorist attacks experienced (in Uganda) at the close of FY 2009/10 increased the need to enhance security measures against terrorism.... To accommodate these priorities, the management of fiscal policy during FY 2010/11 was expansionary compared to the previous year". This resulted in the 2011 government spending shock (49\% growth rate) which forms the gist of this analysis. This paper henceforth analyses the impact of this shock on key economic variables in Uganda.

\section{Contrasting Uganda's Experience with the AD/AS Model}

2.1 Stipulations of the Aggregate Demand /Aggregate Supply (AD/AS) Model

According to macroeconomic theory, when an economy experiences a positive government spending shock, output rises above potential and inflation exceeds its target causing the economy to experience a boom. The central bank 
responds to the rise in inflation by increasing the policy interest rate (contractionary monetary policy), which leads to a decline in output and inflation. Ultimately, output increases by an amount less that the spending shock (UD) and inflation increases but its increment is toned down by the central bank's contractionary monetary policy. This theory is illustrated in figure 2 below with a rightward shift in the AD curve. When the shock passes, the AD curve is expected to shift back, restoring output to potential, and inflation to its target/expectations.

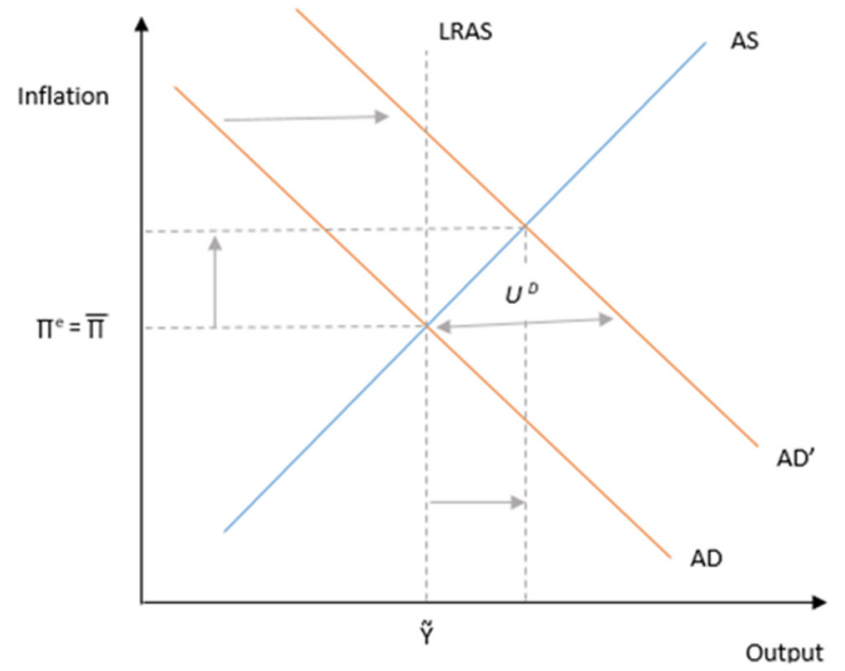

Figure 2: Temporary Impact of a Positive Government Spending Shock - AD/AS Model

2.2 Analysis of the Impact of Uganda's 2011 Government Spending Shock on Aggregate Output, the Real Policy Interest Rate and Inflation Rate.

Figures 3, 4 and 5 below illustrate that when government spending shot up in 2011, the aggregate output (GDP), inflation and real policy interest rates all increased as well. These changes are in line with what the AD/AS model suggests.

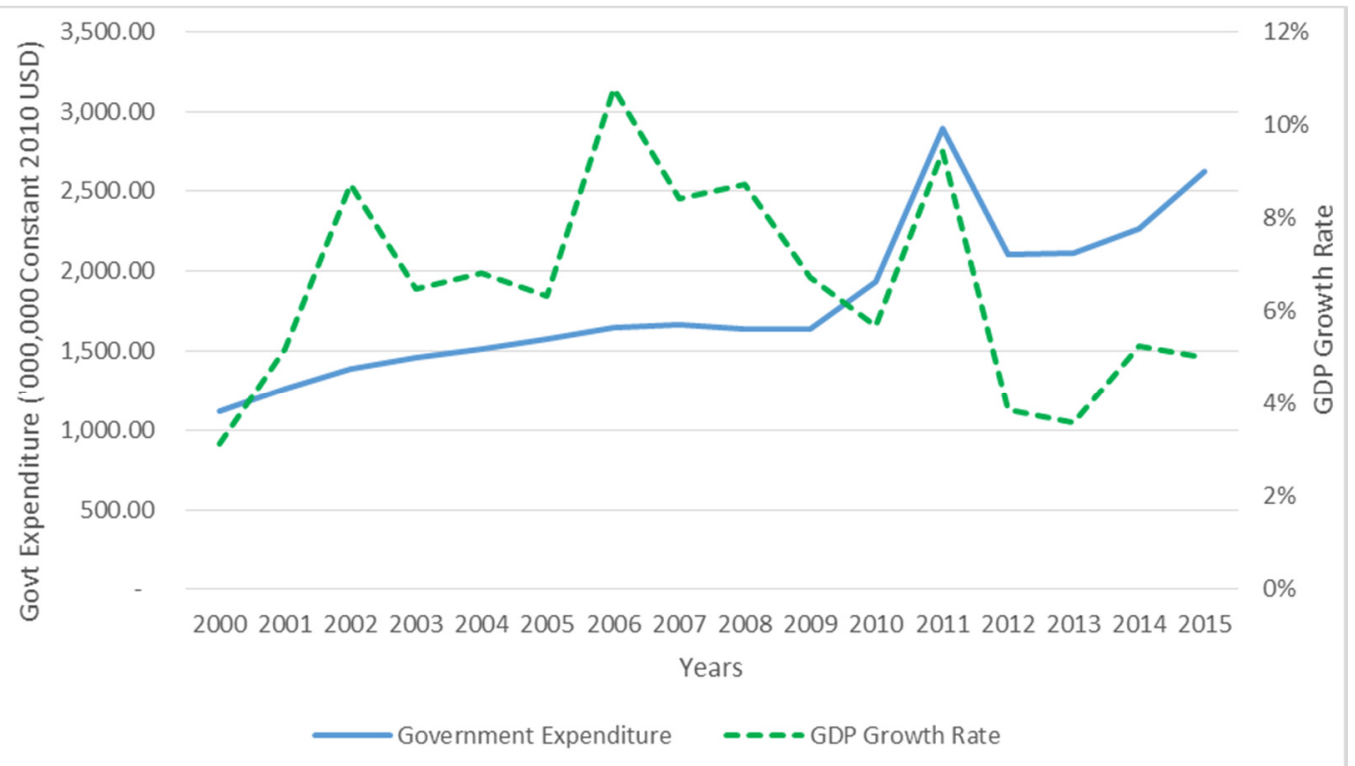

Data Source: World Bank Databases

Figure 3: Uganda's Annual Government Spending and GDP Growth Rate (2000- 2015)

According to World Bank's databases, when Uganda's government spending increased from USD 1.94 billion in 2010 to USD 2.89 billion in 2011 (49\% growth rate) output also increased from USD 20.18 billion in 2010 to USD 22.08 billion in 2011 representing a 9\% growth rate. Figure 3 clearly illustrates the spike in GDP's growth rate in 2011. Graphically, this increment in output would be represented by a rightward shift in Uganda's AD curve. 


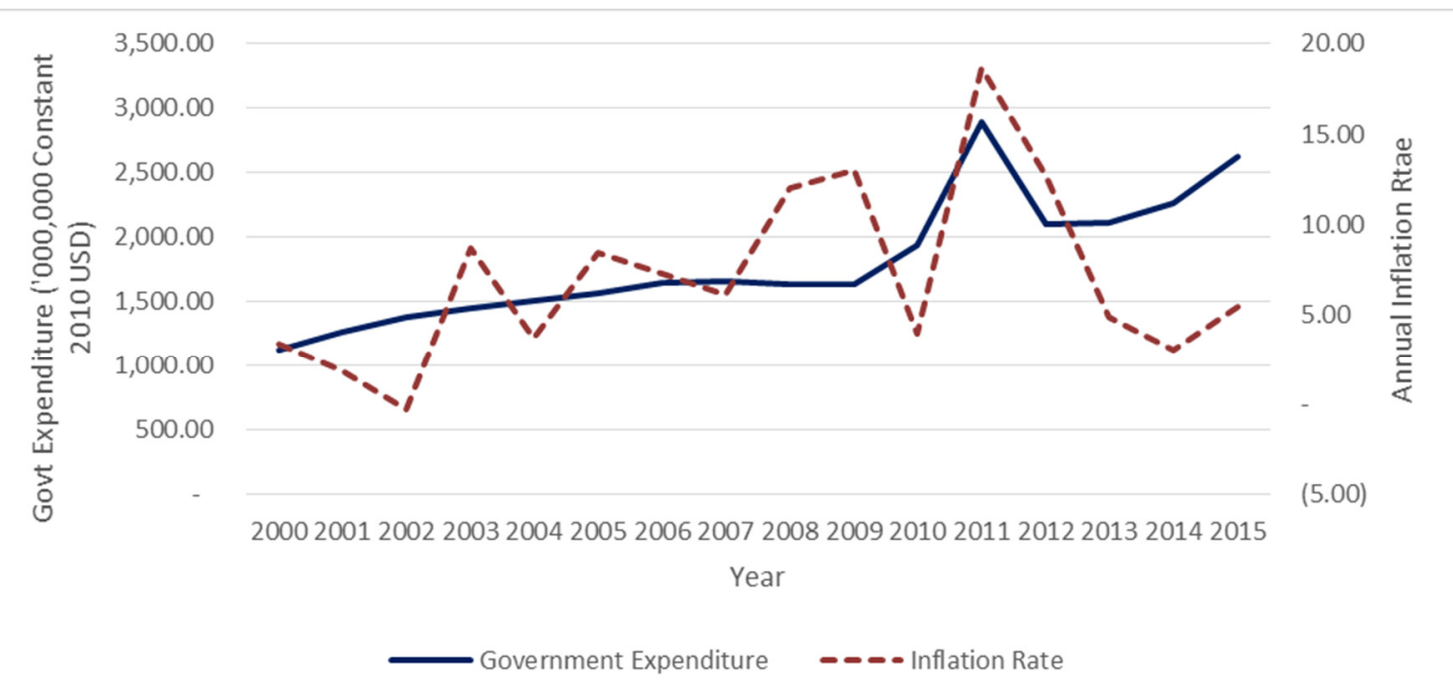

\section{Data Source: IMF and World Bank Databases}

Figure 4: Uganda's Annual Government Spending and Inflation Rate (2000- 2015)

Though in line with theoretical stipulations, the increase in inflation rate following the government spending shock was alarmingly high. According to the AD/AS model, one would expect the implementation of contractionary monetary policy to tone down the inflation outcome. In this case however, inflation rate skyrocketed from $4 \%$ in 2010 to $19 \%$ in 2011 . This suggests probable existence of an additional cause of the inflation upsurge in 2011, perhaps seigniorage.

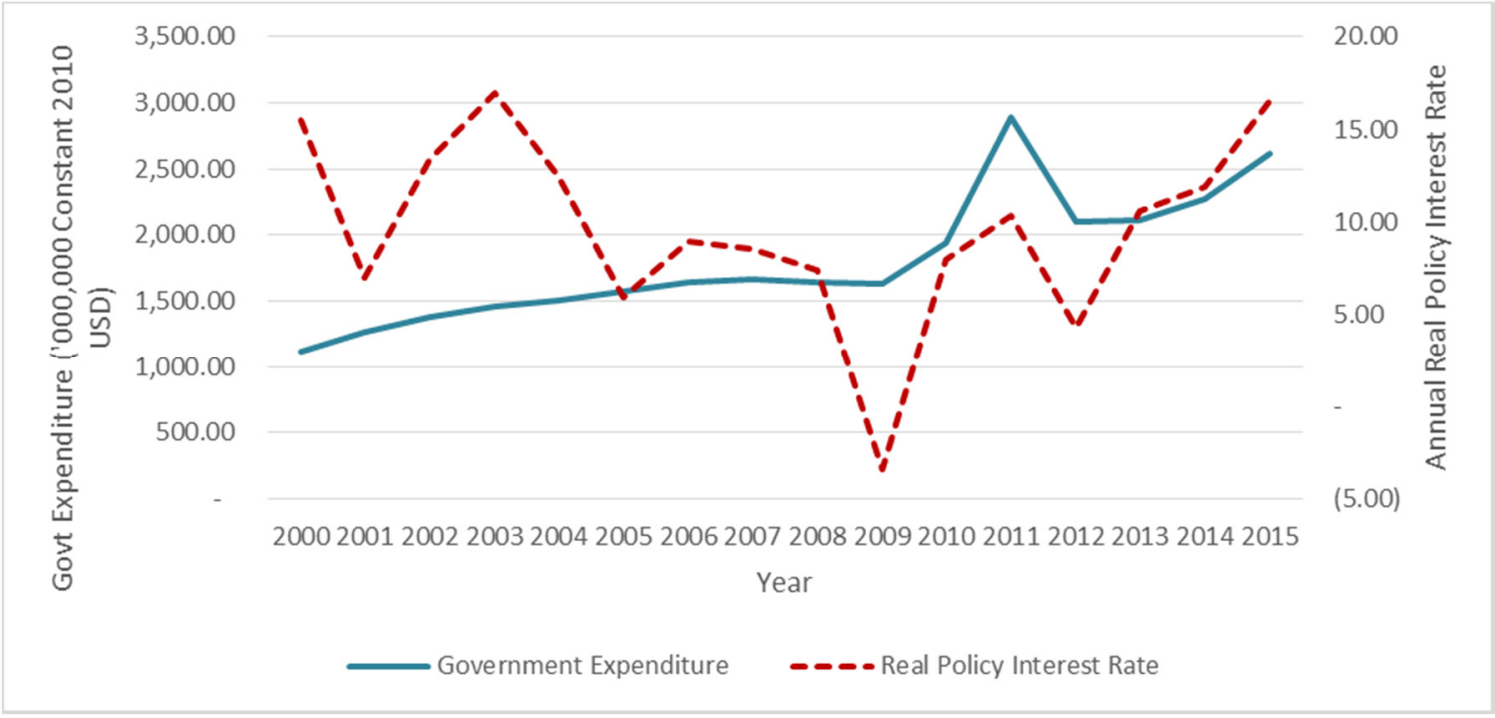

Data Source: IMF and World Bank Databases

Figure 5: Uganda's Annual Government Spending and Real Policy Interest Rate (2000- 2015)

Figure 5 above illustrates that when Uganda experienced a positive government spending shock in 2011, the real policy interest rate increased from $7.99 \%$ in 2010 to $10.31 \%$ in 2011 , an indication of contractionary monetary policy. This is in line with the AD/AS model's predictions.

As the model suggests, after the shock passed (in 2012), output stabilised (its growth rate fell), the inflation rate fell and the policy interest rate fell as well. This illustrates the temporary nature of the shock, which would be illustrated by a backward (leftward) shift in the AD curve.

\section{Crowding Out of Net Exports}

Macroeconomic theory suggests that a positive shock in government spending would result in crowding out of net exports i.e. a fall in net exports.

Figure 6 below shows the movement of Uganda's net exports from 2000 to 2010, illustrating their response to the government spending shock in 2011. 


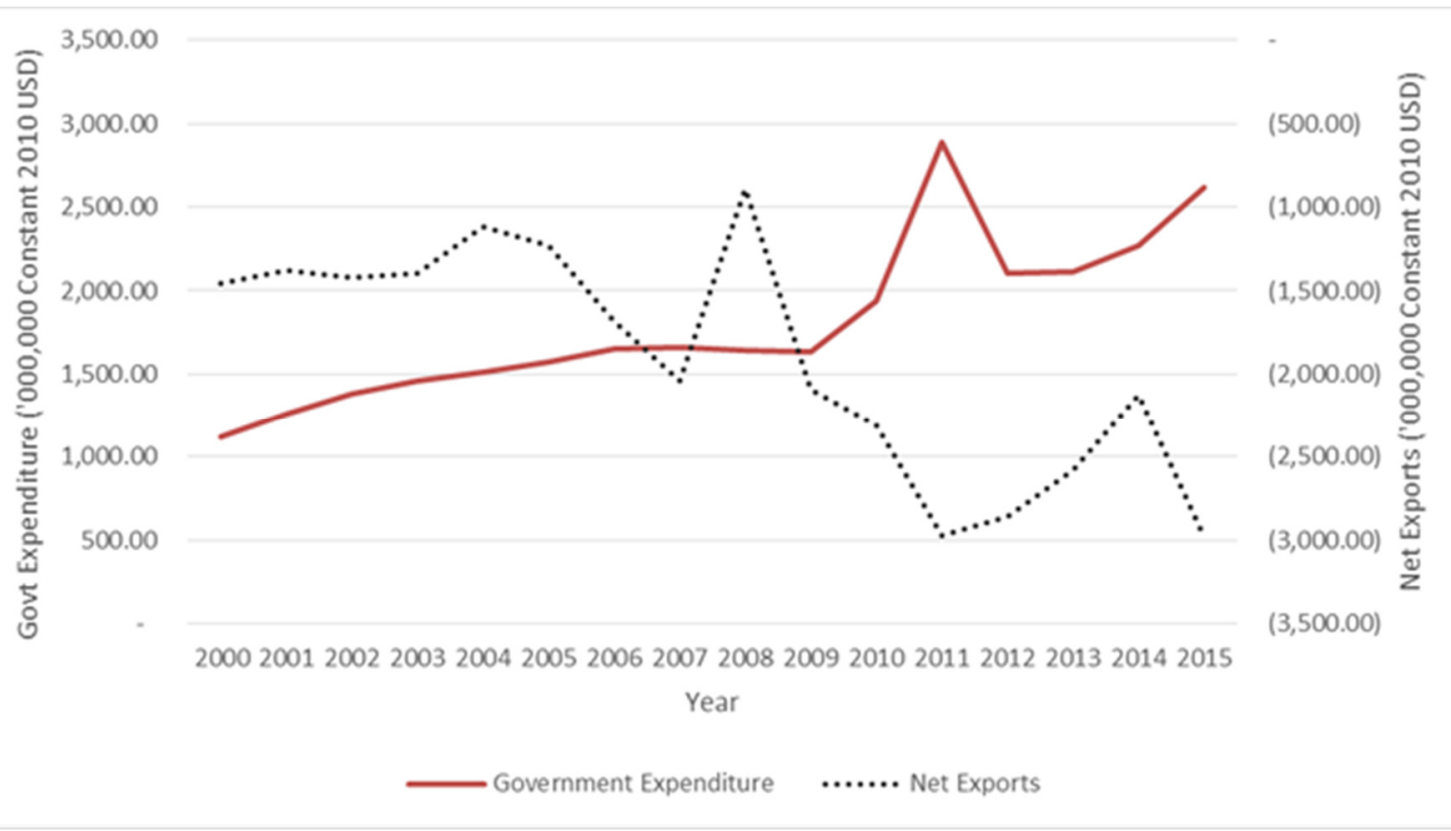

Data Source: World Bank Databases

Figure 6: Uganda's Annual Government Spending and Net Exports (2000 - 2015)

The graph depicts that indeed when Uganda experienced a positive government spending shock in 2011, net exports fell by USD 661.67 million (constant 2010 USD) from -USD 2,312.61 million in 2010 to -USD 2,974.37 million in 2011. Even though on average the Uganda Shilling's real exchange rate against the US Dollar registered a slight depreciation (0.7\% rise) from UGX 2,178 in 2010 to UGX 2,193 in 2011 (World Bank Databases, 2017), Bank of Uganda's statistics indicate that in the later months of 2011 and throughout most of 2012, Uganda's exchange rate registered significant appreciation. In November and December 2011, the end-period exchange rate fell by $8 \%$ and $5 \%$ respectively, and this downward trend continued throughout the bigger part of 2012. This currency appreciation rationalises the apparent crowding out of net exports that is observed in the data.

\section{Conclusion}

When Uganda's economy experienced a positive government spending shock in 2011, its aggregate output, inflation rate and real policy interest rate all responded in line with the $\mathrm{AD} / \mathrm{AS}$ model's predictions. It is important to note however that the increment in the inflation rate was overly great, an indicator that there was perhaps another driver of inflation alongside the government spending shock.

The government spending shock resulted in crowding out of net exports.

\section{References}

Ministry of Finance, Planning and Economic Development; Uganda. 2011. Annual Budget Performance Report $2010 / 11$

\section{Data Sources}

Bank of Uganda Statistics

https://www.bou.or.ug/bou/rates_statistics/statistics.html

IMF Database

http://data.imf.org/?sk=4C514D48-B6BA-49ED-8AB9-52B0C1A0179B\&sId=1390030341854

World Bank Database

http://databank.worldbank.org/data/reports.aspx?source=world-development-indicators\# 